\title{
The role of readers' motivations in the choice of digital versus traditional newspapers
}

Received: 21st July, 2006

\section{Carlos Flavián}

is Professor of Marketing in the Faculty of Economics and Business Studies at the University of Zaragoza. He holds a PhD in Business Administration and his research in strategic marketing and retailing has been published in academic journals such as the European Journal of Marketing, Journal of Consumer Marketing, Journal of Strategic Marketing, International Journal of Bank, Marketing, and different books such as 'The Current State of Business Disciplines, Building Society Through e-Commerce or Contemporary Problems of International Economy'. He is a member of the Editorial Board of the Journal of Retailing and Consumer Services, the Industrial Marketing Management and the Journal of Marketing Communications.

\section{Raquel Gurrea}

is Assistant Professor in the Faculty of Economics and Business Studies at the University of Zaragoza. Her main research lines are online consumer behaviour and the analysis of the advantages and limitations of the internet in the development of economic activity. Her work has been published in several journals, such as Information \& Management and Internet Research, and has been presented at national and international conferences such as the Marketing Science Conference, the International Conference on Recent Advances in Retailing and Services Science, and the European Marketing Academy Conference.

Carlos Flavián Department of Economy and Business Studies C/Gran Via, $n^{\circ} 2$, 50005 Zaragoza, Spain

Tel: +349767 62719 Fax: +34 976761767 Email: cflavian@unizar.es

\begin{abstract}
The development of the internet in recent years is affecting journalism, which is becoming increasingly important on the web. This paper analyses the duality of news media from the demand perspective, identifying the main reasons that draw readers to the media and analysing the influence of such reasons on the decision to read online newspapers rather than traditional print media. The results confirm that the channels could be complementary, if sufficiently differentiated, and may be associated with different motivations and use situations.
\end{abstract}

\section{INTRODUCTION}

Newspaper publishing is one of the activities that has been most affected by the development of the internet. Indeed, the advantages of new digital news media signify nothing short of a revolution in journalism, and the online medium has gone from strength to strength.

With the growing relevance of this service on the web, there has been growing academic interest in research analysing the duality of news media. This duality has raised concerns about a possible transfer of readers from one medium to the other in the newspaper industry itself. From a supply-side perspective, several authors have examined the phenomenon of reader and sales cannibalisation between conventional and digital media. ${ }^{1,2}$ However, literature analysing the demand-side of this duality is still only sketchy.

Journalistic firms therefore need to analyse and understand readers' needs. Knowledge of readers' needs and goals would be an ideal starting point for developing marketing strategies. In this manner, firms could offer readers what they want at any given place and moment.

Thus, the present paper focuses on 
readers' motivations and behaviour when they have the opportunity to choose between or simultaneously consult digital and conventional newspapers. To this end, the objectives of the research are to identify the basic reasons for reading the news, to analyse the possible influence of the reasons identified on the decision to read online or conventional newspapers, and consequently, to study the possible complementarity between both types of news media.

The following section emphasises the growing importance of internet news media. The third section analyses the reasons that lead readers to consult the news. Subsequently, the choice of digital versus traditional newspapers is analysed, after which the process of depurating and validating the scales and the main results are presented. Finally, the paper offers a series of conclusions and managerial implications.

\section{THE PRESS SECTOR AND THE INTERNET}

The appearance of new digital media has brought far-reaching changes in the press sector. ${ }^{3}$ There has been a transformation at the organisational level, the creation of a specific language, and a new multimedia environment. All these imply the arrival of new challenges and opportunities in the near future. ${ }^{4}$ Indeed, editorial offices are now working in a different way and with a quicker pace than compared with the traditional medium. ${ }^{5}$ For example, shorter texts, with a 'faster' language, are used in the electronic channel because the main goal is to provide constant updated information and accessibility to the news. ${ }^{6,7}$ In view of this metamorphosis, the internet may well be said to have changed popular conception of what constitutes a newspaper. ${ }^{8}$

The advantages of the internet have brought about a revolution in journalism. The use of these new systems is distinguished by the speed with which news items reach the reader, the low cost of distributing information and the opportunity to establish direct contact and interaction with users, who have come to play an important role in the design of the journalistic product. Finally, one must note that the internet combines the three basic advantages of radio, press and television. This new medium presents the immediacy of the radio, the wide and deep information offered by the press and the impact of the images in television. Together, these aspects configure a complete journalistic product. Thus, there are currently over 4,200 digital newspapers worldwide. ${ }^{9,10}$

In addition, digital news and newspapers are among the services most avidly sought by internet users. ${ }^{11-14}$ News sites and, of course, digital newspapers are among the most widely demanded and visited websites within the internet community worldwide. Kaye and Johnson ${ }^{15}$ affirm that the main aim of users accessing the internet is to read breaking news and search for up-to-the minute information (83.7 per cent), only exceeded by the use of email. Similarly, data provided by Harris Interactive $^{16}$ show that 80 per cent of US surfers read news online, preferring the websites of digital newspapers in 45 per cent of cases. Pew Research Center for the People and the Press, ${ }^{17}$ meanwhile, affirm that one in three Americans visited online newspapers and anticipated sharp growth in the number of users consulting current news items on these sites. Finally, the Online Publishers Association ${ }^{18}$ concludes that 83 per cent of respondents to its survey clearly prefer to read news online. 


\section{DIGITAL VERSUS PRINT}

There is currently no overall model to identify and explain the main reasons that lead readers to consult the news. In view of this gap in the literature, not to mention the interest evinced by newspaper publishers in knowing the reasons and needs of the readers of current news stories in the new digital medium, ${ }^{19}$ there is a clear need for an overall analysis to account for the effects of the various motivations simultaneously.

To this end, the preliminary stages of the present research began by way of an exploratory investigation. Specifically, the first step consisted of defining and bringing together a focus group with the aim of the researchers familiarising themselves more deeply with the subject of analysis and making an initial approach to the attitudes and behaviour of newspaper readers. ${ }^{20}$ A series of in-depth interviews with a sample of readers of both digital and traditional newspapers was then held. These results were enormously useful in fleshing out the scope of the research and progressing with the research as they highlighted the importance of certain factors that have not been considered in detail in the existing literature. ${ }^{21}$ Once the qualitative studies had been analysed, some of the basic reasons that lead readers to consult or read the news were identified:

- Search for specific information (SSI). Many of the readers interviewed affirmed that they sought specific data of special personal interest in the newspaper, such as stock prices, sports results, and so on.

- Search for updated news (SUN). Another reason for reading a daily newspaper is the desire to keep abreast of breaking news (ie the latest events) or to follow current affairs.

- Leisure - Entertainment (LEIS). Many of interviewees said that they would frequently begin reading current information in the newspaper to pass time or entertain themselves. Thus, reading the news takes up a part of the reader's leisure time, while they acquire knowledge of current affairs.

- Habit (HAB). There is a significant segment of newspaper readers motivated by a habit acquired over time and generally associated with a given time of day, when they will read or leaf through the newspaper almost systematically.

It seems logical that the internet has had an impact on readers' motivations and their reading and information search habits. ${ }^{22-24}$ Thus, it is necessary to establish which of the reasons leading people to read the news significantly influence the choice of digital rather than traditional newspapers.

It would seem reasonable to assume that people with a need to obtain specific information will turn naturally to online news, as the ease of search and comparison is one of the factors differentiating the internet from physical media. ${ }^{25,26}$ Tessio $^{27}$ argues that digital versions of newspapers are aimed at the pragmatic reader, who seeks information that is relevant to his needs and ignores matters of no immediate interest. Furthermore, the internet may thus be viewed as a vital research medium allowing the user to search for needed information. ${ }^{28,29}$ So, it seems reasonable to suppose that one of the basic reasons for reading the news online is the need to find precise information on a given subject.

Other reasons possibly associated with digital rather than traditional newspapers could be the search for updated news. ${ }^{30}$ This is due to the immediacy and updates that are key features of the internet and are closely bound up with breaking news. ${ }^{31,32}$ This was clearly 
demonstrated by the pattern of internet use in the wake of recent world events such as the September 11 terrorist outrage $^{33}$ and the March 11 train bombing in Madrid.

However, other reasons may be more closely associated with traditional rather than digital versions of newspapers. Thus, entertainment would be closely linked to the behaviour of readers of the print version. Indeed, Stephenson ${ }^{34}$ pointed out that reading traditional printed media was associated with leisure moments. Meanwhile, Bogart ${ }^{35}$ showed that reading was relaxed and detailed when people read their daily news on paper.

Similarly, the results of the qualitative study suggest that reading frequently takes place as a result of a daily habit of looking at the newspaper at given times of day or in certain situations. In addition, according to Len Ríos and Bentley, ${ }^{36}$ reading the news out of habit is of considerable importance in explaining the use of paper formats of news delivery. Consequently, the habit would be the least closely related with reading or consulting digital newspapers.

\section{DATA COLLECTION}

To develop scales to measure the various motivations for reading the news, an exhaustive review of the specialist literature was undertaken, as well as a search for existing scales that could be suitably adapted. Given the relative scarcity of the existing literature, however, it was necessary to take the problem further by undertaking a series of preliminary qualitative studies. ${ }^{37}$

Having established the context of the analysis and designed a series of questions that would pick up the various factors involved, the next step was to carry out the survey itself. It was decided to do this via the internet because the target demographic for the study was internet users, who have the opportunity to read the news online and are therefore in a position to choose to read the digital rather than traditional newspapers.

The final questionnaire was then prepared and published on a website designed specifically for the purpose of the research. This site presented the research and its objectives and offered the possibility of downloading the questionnaire, allowing respondents to answer on paper or using their PCs and return it by email, fax or conventional mail. Information was sent to various distribution lists associated with a range of subjects, and banners were placed on the websites of electronic newspapers in order to disseminate the existence of the research. Variables were analysed using seven-point Likert scales.

A total of 253 valid responses were obtained from April to June 2004. This gave a sample error of 6.2 per cent (at a 95.5 per cent level of confidence and with infinite populations). The representative nature of the sample could be guaranteed by the similarity of the profile of the interviewees with that obtained in recent studies, such as those by Asociación Española de Comercio Electrónico $^{38}$ or Asociación para la Investigación de Medios de Comunicación. ${ }^{39}$ More specifically, the majority of interviewees were male (61.1 per cent) and aged between 25 and 34 years (47.1 per cent). In general, they were well educated with 82.2 per cent of the sample holding a higher education qualification. The majority of the respondents also had over five years' experience of computers (83.6 per cent) or as internet users (51.6 per cent).

\section{PROCESS OF SCALES REFINEMENT AND VALIDATING}

To obtain scales that would allow the valid and reliable quantification of the 
motivations of newspaper readers, a process of fine-tuning was undertaken, structured in two stages. First, a reliability and unidimensionality analysis was conducted, and secondly the content and construct validity of the proposed scales were checked.

\section{Reliability and unidimensionality analysis}

The first step to guarantee the scales' reliability was to calculate Cronbach's alpha value ${ }^{40}$ and the item-total correlation of each of the variables analysed. ${ }^{41,42}$ As a second stage in the previous exploratory analyses of the scales, a study of unidimensionality in each scale was carried out by means of an exploratory factor analysis. ${ }^{43,44}$

To guarantee the proposed scales' reliability and validity, a series of confirmatory analyses was carried out, according to the methodology of confirmatory model development. ${ }^{45}$ This methodology enables one to sift scales by the development of successive confirmatory factor analyses. With this aim, those items which did not meet the three criteria proposed by Jreskog and Srbom were successively eliminated. ${ }^{46,47}$ Acceptability of the goodness of fit of the complete confirmatory model was then checked.

The reliability levels of each indicator, expressed in terms of $R^{2}$, were all found to be acceptable, taking into account a minimum value of 0.5 . To confirm the definitive reliability of the scales, tests of the composite reliability coefficient ${ }^{4}$ and the average variance extracted ${ }^{49}$ were carried out.

\section{Validity analysis}

The necessary validity analyses were carried out to verify whether the designed scales correctly measured the concepts.
- Content validity: No statistical tests exist that would guarantee the validity of the scale contents. In general, the validity of a scale's content may be accepted if it has been developed on the basis of existing theories in the relevant literature. In the present case, validity may be considered to be guaranteed not only in view of the rigour employed in the design of the initial scales on the basis of the literature ${ }^{50-54}$ but also because the results and conclusions of the in-depth interviews carried out, which were endorsed by various experts in the subject, have been taken into account.

- Construct validity: To asses construct validity convergent validity and discriminatory validity were checked, ${ }^{55}$ achieving satisfactory results in both cases.

On the basis of preliminary work, it was possible to establish the definitive scales to measure each of the variables considered in this study (see Appendix 1).

\section{READERS' BEHAVIOUR PATTERN}

Before analysing the relationships between the reasons for reading and the choice of digital versus traditional newspapers, it is necessary to explain some descriptive results that could indicate some preliminary conclusions with important implications for this research. Thus, to approach the analysis of the different aspects which might have a bearing on the analysis of newspaper reading behaviour, a $t$-test on mean differences for paired samples was run. For this purpose, the questionnaire posed a series of aspects to characterise the typology of newspaper reading by the respondent. Readers were asked to indicate their degree of agreement or disagreement with the statements through 
Table 1: Digital vs. traditional hehaviour patterns

\begin{tabular}{ll}
\hline & Mean difference \\
\hline Traditional newspapers & \\
Focus your attention on specific information & $-1.36^{\star \star}$ \\
Focus your attention on specific topics & $-0.84^{\star \star}$ \\
Read fairly quickly & $-0.91^{\star \star}$ \\
Skim and scan initially, focusing your attention later on news of greater interest & $-0.30^{\star}$ \\
Read at moments associated with job & $-1.52^{\star \star}$ \\
Digital newspapers & $0.69^{\star}$ \\
Read all types of news in a newspaper & $0.78^{\star \star}$ \\
Read entire newspaper & $1.08^{\star \star}$ \\
Read in a relaxed manner & $0.78^{\star \star}$ \\
Read in a detailed manner & $1.46^{\star \star}$ \\
Read in free time & $1.57^{\star *}$ \\
Read at home or outside the workplace & \\
\hline
\end{tabular}

${ }^{*}$ Coefficients significant to 0.05 level

${ }^{* *}$ Coefficients significant to 0.01 level

Table 2: Reading the newspaper: week days and frequency

\begin{tabular}{lll}
\hline & $\begin{array}{l}\text { Traditional } \\
\text { newspaper (\%) }\end{array}$ & $\begin{array}{l}\text { Digital } \\
\text { newspaper (\%) }\end{array}$ \\
\hline $\begin{array}{l}\text { When do you most often read newspapers? } \\
\text { Working week }\end{array}$ & 30.8 & 78.4 \\
Weekend & 69.2 & 21.6 \\
Newspaper reading frequency & & 36.6 \\
Several times a day & 0.9 & 40.1 \\
Every day & 37.6 & 15.1 \\
Several times a week & 35.1 & 6.3 \\
Sometimes & 21.9 & 1.9 \\
Hardly ever & 4.5 & \\
\hline
\end{tabular}

a Likert scale of seven points - from 'totally disagree' (1) to 'totally agree' (7), in each medium.

The results highlight that reading newspapers on the internet is characterised by being focused on specific subjects, fairly rapid, particularly in the initial moments, before going deeper into major interest and work-linked news. By contrast, the news in traditional format is read more thoroughly, in a more detailed, relaxed manner, and is associated with free time (Table 1). It is therefore possible to defend the existence of a clear duality of newspaper reading behaviour in the physical and digital environment.

Table 2 describes the different habits for reading traditional/digital newspapers. More specifically, traditional newspapers are mostly read at the weekend, while digital news is more commonly read on working days. In addition, most of the interviewees read conventional newspapers every day or several times a week. On the other hand, 76.7 per cent of the sample read electronic newspapers with a higher frequency.

The results confirm significant differences between the most valued attributes of digital news and the traditional daily newspaper. Readers were asked to valuate different attributes of a newspaper using a seven-point Likert scale, from 'not important' (1) to 'very important' (7), in each medium . To verify this, a $t$-test on mean differences for paired samples was run (see Table 3). More specifically, results show that immediacy, accessibility and free cost are the most relevant attributes for electronic news, while writing style is very important in traditional news. Nevertheless, three attributes do not 
Table 3: Digital vs. traditional newspaper attributes

\begin{tabular}{ll}
\hline & Mean difference \\
\hline $\begin{array}{l}\text { Traditional newspapers } \\
\text { Writing style }\end{array}$ & $-0.27^{\star}$ \\
Digital newspapers & \\
Immediacy/Update & $2.16^{\star}$ \\
Free charge & $2.58^{\star}$ \\
Convenience & $0.48^{\star}$ \\
Design & $0.63^{\star}$ \\
Accessibility/Interactivity & $2.14^{\star}$ \\
Readers' services & $0.57^{\star}$ \\
\hline
\end{tabular}

${ }^{*}$ Coefficients significant to 0.01 level

present significant differences between either channel: editorial firm's reputation, sources' quality and sources' reliability: These results are reasonable, as these aspects are important for any reader, regardless of whether they read digital or traditional news.

\section{THE INFLUENCE OF READERS' MOTIVATION}

A binary logistic regression analysis was tested. This statistical analysis predicts the likelihood that one of the options for the dependent variable will occur based on a series of independent variables. ${ }^{56}$ The dependent variable reflects responses to the question of whether or not individuals read news online. The independent variables are the four motivations that lead people to read the news as independent variables. These were calculated in terms of the arithmetical average of all of the items comprising each of the refined scales.

Individually, the significance of each of the variables included in the analysis was measured using Wald's statistical test. As may be observed in Table 4, both the SUN variable and LEIS and HAB exhibit significant values at 99 per cent. Nevertheless, the score obtained for the variable representing the first motive (SSI) is not significant. The overall significance of the regression coefficients was confirmed using a $g$-test. This test exhibits a $\chi^{2}$ of $60.188(4 \mathrm{df})$ and a level of signification of 0.00 . The overall significance of the model is thus guaranteed.

It was also necessary to analyse the model's goodness of fit. In the first place, it was possible to establish global goodness of fit on the basis of the value of $-2 \log$ likelihood of the model:

107.359. ${ }^{57}$ The Hosmer-Lemeshow test was also performed. The results indicate that the proposed model provides a satisfactory fit with the data $\left(\chi^{2}=3.717\right.$; $\mathrm{df}=8 ;$ significance $=0.882)$

Finally, the Huberty test was performed with the aim of analysing the predictive power of the model. The results validate the statistical significance of the overall correct prediction rate. In addition, the predictive power of the model is high, with a correct prediction rate of 92.1 per cent.

Taking into account the significance and the proposed model's overall goodness of fit and predictive power, it is possible to confirm that the regression is adequate for analysing the motivations that might influence the decision to use

Table 4: Results of the logistic regression

\begin{tabular}{lccr}
\hline Variables & $\boldsymbol{\beta}$ & Exp $(\boldsymbol{\beta})$ & Wald \\
\hline SSI & -0.079 & 0.024 & 0.221 \\
SUN & $1.197^{\star}$ & 3.309 & 27.130 \\
LEIS & $-0.520^{*}$ & 0.595 & 6.640 \\
HAB & $-0.571^{*}$ & 0.565 & 8.914 \\
Constant & 1.135 & 3.111 & 0.472 \\
\hline
\end{tabular}

${ }^{*}$ Coefficients significant to 0.01 level

$\mathrm{df}=1$ 
the internet to read the news. Thus, the model did not substantiate the existence of any significant relationship between motivation based on the search for specific information (SSI) and reading the online news. However, it has been established that the motivation to search for updated news (SUN) does influence online reader behaviour. As this relationship is positive, the more motivated a reader is to search for current news items immediately, the more likely it is that they read the digital rather than the traditional paper medium. Finally, the last two variables considered (leisure and entertainment [LEIS] and habit [HAB]) exhibit high levels of significance and a negative relationship with reading online newspapers. This implies that the more motivated an individual is to read the news for pleasure, or merely out of habit, the less likely they will choose the digital over the traditional medium.

\section{CONCLUSIONS AND DISCUSSION}

This paper has sought to identify why people read newspapers and to develop a model that accounts for the basic motivations for reading the digital rather than the traditional medium. The analysis confirms the existence of a significant positive relationship between motivation related to the search for updated news and online news readership. Motivations related to reading as entertainment or habit clearly have a significant negative influence on the choice of digital medium for newspaper reading. Nevertheless, a significant relationship between the motivation linked to the search for specific information and online news readership has been observed.

This could be because online journalism is still at an early stage of development, despite the enormous relevance it has already acquired. At this early stage, readers using the internet to access the news are still relatively inexperienced and unfamiliar with the service. This unfamiliarity with the medium may complicate online reading of newspapers to some extent.

Furthermore, readers may consider the degree of knowledge of the medium and the website required for specific data searches as a disincentive. Nevertheless, this phenomenon may well fade away in a relatively short time, given the speed of progress made by the newspaper sector in the electronic medium.

Another factor that could explain the lack of a clear relationship between specific information needs and consultation of the digital rather than the traditional news would be the weakness of the search engines currently provided by digital newspapers. These search engines are largely underdeveloped and offer few options to readers with specific information needs. Thus, readers frequently find that their searches do not generate the desired results as quickly as they may wish.

In conclusion, this research could represent a step forward in the context of this analysis and would remove some newspaper industry concerns about the possible cannibalisation of readers between the physical and digital media. A similar phenomenon also occurred in the second half of the 20th century when the television started to operate versus the radio. However, time has shown that both media are clearly perceived by users as different informative and entertainment products. This is because these media are focused on different targets or situations for use.

A study limitation worth noting is that the sample is restricted to readers of Spanish language newspapers. However, the representativeness of the sample could be guaranteed because the Spanish 
language is the fourth most common language used on the internet. ${ }^{58} \mathrm{In}$ addition, certain variables defining readers' motivations for reading digital news may have been passed over. In this regard, future research may be warranted, possibly including new explanatory factors in the model to describe reading behaviour.

\section{MANAGERIAL IMPLICATIONS}

There are significant implications for management. The main aspects justifying digital newspaper reading should be considered by management personnel in this type of news medium, in order to potentate its use. Indeed, journalistic firms should take advantage of the internet's possibilities and explore this as an avenue for development. In such a way, they could have undoubted future opportunities.

If conclusive evidence for the relationship between readers' objectives and the format used to pursue them were provided, this could enable publishers to progress with the differentiation of the services offered via the two media and achieve a better fit with reader preferences. Indeed, it seems probable that if the printed version and the digital version of the same newspaper are positioned adequately, readers would thus perceive these services as complementary products meeting the same generic need (obtaining current information), but with varying features for use in different contexts. Thus, reading the printed version of a newspaper may be more advisable for eyesight than the digital version and may also be preferred when the reader has more time, or is interested in reading a major part of the content of the newspaper. Alternatively, reading a digital newspaper may be preferred if the reader is looking for a brief overview of the news of the day; if they are looking for the latest information, which has not been published in the printed version; or if only a few specific facts are being sought.

However, it would be wise for newspaper publishers to develop the search engines offered on their websites and improve search facilities for users. Search engines should provide readers with fast, helpful results, while websites could be better structured to make them simpler to use and navigate. This would help overcome the barriers to digital media use where the reader is motivated by the need to find a specific piece of information.

In any case, it is evident that digital journalism is an alternative way of providing news, which is becoming increasingly consolidated and opening up its own niche within the business of journalism. Companies who propose to offer both the printed and digital medium simultaneously should therefore bear in mind the new opportunities and possibilities that the internet offers for the newspaper business.

\section{Acknowledgments}

The authors are grateful for the financial support received from the Spanish Ministry of Science and Technology (SEC2005-4972; PM34) and the Aragón Goverment (S-46).

\section{References}

1 Deleersnyder, B., Geyskens, I., Gielens, K. and Dekimpe, M. (2002) 'How cannibalistic is the internet channel? A study of the newspaper industry in the United Kingdom and The Netherlands', International Journal of Research in Marketing, Vol. 19, No. 4, pp. 337-348.

2 Gilbert, C. (2001) 'A dilemma in response: Beyond resource allocation. Examining the newspaper industry's response to the internet', unpublished doctoral dissertation, Harvard Business School, Boston, MA.

3 Bush, V. and Gilbert, F. (2002) 'The web as a medium: an exploratory comparison of internet users versus newspaper readers', Journal of Marketing Theory and Practice, Vol. 10, No. 1. pp. 1-10.

4 Dans, E. (2000) 'Internet newspapers: Are some more equal than others?', The International Journal on Media Management, Vol. 2, No. 1, pp. 4-13.

5 Greer, J. and Mensing, D. (2003) 'The evolution of 
online newspapers: A longitudinal content analysis, 1997-2003', paper presented at the Newspaper Division of the Association for Education in Journalism and Mass Communication Annual Conference, July.

6 Asociación para la Investigación de Medios de Comunicación (2005) www.aimc.es/aimc.php.

7 Mediabriefing (2005) 'La prensa ensaya fórmulas de sinergia con Internet', www.mediabriefing.com/ actualidad.asp?idarticulos $=1353$.

8 Dans, ref. 4 above.

9 Editor \& Publisher (2005) 'Newspaper web sites continue to gain readers', www.editorandpublisher.com/eandp/departments/ online.

10 World Newspapers Online (2005) 'Online newspapers in the world', www.actualidad.com.

11 Eveland, W., Marton, K. and Seo, M. (2004) 'Moving beyond 'Just the facts', The influence of online news on the content and structure of public affairs knowledge', Communication Research, Vol. 31, No. 1, pp. 82-108.

12 Consoli, J. (1997) Online usage: 'More than a fad', Editor \& Publisher, Vol. 130, No. 32, p. 26.

13 Levins, H. (1998) 'Growing US audience reads news on net', Editor \& Publisher, Vol. 131, No. 8, p. 14.

14 Newspaper Association of America (2003) 'Online newspapers are the top source for local news on the web', www.naa.org/Global/

PressCenter/2002/ONLINE-NEWSPAPERS-ARETHE-TOP-SOURCE-FOR-LOCAL-NEWSON-THE-WEB.aspx?lg=naaorg.

15 Kaye, B. and Johnson, T. (2004) 'A web for all reasons: Uses and gratifications of internet componentes for political information', Telematics and Informatics, Vol. 21, No. 3, pp. 197-223.

16 Harris Interactive (2004) 'Internet grows as primary source of news and information', http://www. harrisinteractive.com/harris_poll/index.asp?PID=464.

17 Pew Research Center for the People and the Press (2000) 'The Internet news audience goes ordinary', people-press.org/reports/display.php3?ReportID=72.

18 Online Publisher Association (2004) 'Generational media study', www.online-publishers.org/pdf/ opa_generational_study_sep04.pdf.

19 Althaus, S. and Tewsksbury, D. (2002) 'Agenda setting and the 'new' news: patterns of issue importance among readers of the paper and online versions of the New York Times', Communication Research, Vol. 29, No. 2, pp. 180-207.

20 Edmunds, H. (1999) 'The Focus Group Research Handbook', NTC Business Books, Chicago.

21 De Ruyter, K. and Scholl, N. (1998) 'Positioning qualitative market research: from theory and practice', Qualitative Market Research: An International Journal, Vol. 1, No. 1, pp. 7-14.

22 Dimmick, J., Chen, Y. and Li, Z. (2004) 'Competition between the internet and traditional news media: The gratification-opportunities niche dimension', The Journal of Media Economics, Vol. 17, No. 1, pp. 19-33.

23 Hujanen, J. and Pietikäinen, S. (2004) 'Interactive uses of journalism: Crossing between technological potential and young people's news-using practices', New Media \& Society, Vol. 6, No. 3, pp. 383-401.

24 Althaus and Tewsksbury, ref 19 above.

25 Brown, M. (2000) 'Bringing people closer to news', Adweek, Vol. 41, No. 40.

26 Asociación Española de Comercio Electrónico (2005) 'Estudio sobre comercio electrónico B2C', observatorio.red.es/estudios/documentos/ estudio\%20_b2c_2005.pdf.

27 Tessio, S. (2002) 'Periodismo electrónico y prensa gráfica: ¿Gatopardismo de lenguajes, agendas telemáticas y lectores, en una nueva-vieja propuesta comunicacional?', Jornadas Redcom, Buenos Aires, Argentina, November.

28 Schönbach, K. and Lauf, E. (in press) 'Another look at the 'trap' effect of television and beyond', International Journal of Public Opinion Research, Vol. 16, No. 2, pp. 169-182.

29 De Waal, E., Schönbach, K. and Lauf, E. (2004) 'Online newspapers: A substitute for print newspapers and other information channels?', paper presented at 6th World Media Economics Conference, Canada, 12-15 May.

30 Rathmann, T. (2002) 'Supplement or substitution? The relationship between reading a local print newspaper and the use of its online version', Communications, Vol. 27, No. 4, pp. 485-498.

31 Brown, ref. 25 above.

32 Chyi, H. and Lasorsa, D. (2002) 'An explorative study on the market relation between online and print newspaper', The Journal of Media Economics, Vol. 15, No. 2, pp. 91-106.

33 Kim, Y., Jung, J., Cohen, E. and Ball-Rokeach, S. (2004) 'Internet connectedness before and after September 11 2001', New Media \& Society, Vol. 6, No. 5, pp. 611-631.

34 Stephenson, W. (1967) 'The Play Theory of Mass Communication', University of Chicago Press, Chicago.

35 Bogart, L. (1992) 'The state of the industry', in Cook, P., Gomery, D. and Lichty, W. (eds) 'The Future of News', Woodrow Wilson Center Press, Washington, DC, pp. 85-103.

36 Len Rios, M. and Bentley, C. (2001) 'Use of online news site: Development of habit and automatic procedural processing, paper presented at AEJMC Conference, Washington, DC, August.

37 Barker, M. (2003) 'Assessing the 'quality' in qualitative research', European Journal of Communication, Vol. 18, No. 3, pp. 315-335.

38 Asociación Española de Comercio Electrónico, ref. 26 above.

39 Asociación para la Investigación de Medios de Comunicación, ref. 6 above.

40 Cronbach, L. J. (1970) 'Coefficient alpha and the internal structure of test', Psychometrika, No. 16, Oct., pp. 297-334.

41 Bagozzi, R. P. (1981) 'Evaluating structural equations models with unobservable variables and measurement error: a comment', Journal of Marketing Research, Vol. 18 (August), pp. 375-381. 
42 The scales were filtered on the basis of these criteria, resulting in the elimination of certain indicators. Having eliminated these items, the results of Cronbach's alpha test showed an acceptable degree of internal consistency in the five scales considered, with scores in all the cases over the 0.7 recommended by Cronbach. In addition, the item-total correlation of each indicator was higher than the 0.3 points recommended by Nurosis (1993) 'SPSS. Statistical Analysis Data', SPSS Inc.

43 McDonald, R. P. (1981) 'The dimnsionality of test and items', British Journal of Mathematical and Statistical Psychology, Vol. 34 (May), pp. 100-117.

44 Factorial analysis revealed the existence of a single factor in the five scales, which respectively explained $57.270 \%, 67.186 \%, 76.439 \%, 55.145 \%$ and $89.840 \%$ of variances. Furthermore, the factor loadings were above 0.5 points (Hair et al., 1999).

45 Hair, J. F. Jr., Anderson, R. E., Tatham, R. L. and Black, W. C. (1999) 'Multivariate Analysis', Prentice Hall, Madrid.

46 Jöreskog, K. G. and Sörbom, D. (1993) 'LISREL 8: Structural Equation Modeling with the SIMPLIS Command Language', Scientific Software International, Chicago, IL.

47 Criteria of weak convergence would eliminate indicators that did not have a significant factorial regression coefficient ( $t$-student > 2.58: $p=0.01$ ). Criteria of strong convergence would eliminate those indicators that were not substantial, ie those whose standardised coefficient is less than 0.5. Lastly, Jöreskog and Sörbom (see ref. 46 above) propose the elimination of those indicators that least contribute to the explanation of the model, considering the cut-off point as $R^{2}<0.3$.

48 Jöreskog, K. (1971) 'Statistical analysis of sets of congeneric tests', Psychometrika, Vol. 36, pp. 109-133.

49 Fornell, C. and Larcker, D. (1981) 'Structural equation models with unobserved variables and measurement error', Journal of Marketing Research, Vol. 18, pp. 39-50.

50 De Waal et al., ref. 29 above.

51 D'Haenens, L., Jankowski, N. and Heuvelman, A. (2004) 'News in online and print newspapers: differences in reader comsumption and recall', New Media \& Society, Vol. 6, No. 3, pp. 363-382.

52 Van Oostendorp, H. and Van Nimwegen, C. (1998) 'Locating information in an online newspaper', Journal of Computer-Mediated Communication, Vol. 4, No. 1, pp. 1-10.

53 Watters, C., Shepherd, M. and Burkowski, F. (1998) 'Electronic news delivery project', Journal of the American Society for Information Science, Vol. 49, No. 2, pp. 134-150.

54 Marath, A., Shepherd, M. and Watters, C. (2002) 'Adaptative user modelling for filtering electronic news', Paper presented at 35th Annual Hawaii International Conference on Systems Sciences, 7-10 January, Vol. 4.

55 To assess convergent validity, the standardised coefficients in each scale were confirmed to be over 0.5 and significant. Several tests were used to assess discriminatory validity, such as checking that value ' 1 ' was not in the confidence interval of the correlations between different constructs. Likewise, it was checked that correlations between different scales were not over 0.8 .

56 Hair et. al, ref. 45 above.

57 The value obtained, -2loglikelihood of the model $=107.359$, was tested by comparison with the theoretical value of the $\chi^{2}$ distribution with $(\mathrm{N}-\mathrm{p})$ g.1., where $\mathrm{N}$ is the total number of data and $\mathrm{p}$ is the number of parameters included in the model. Specifically, we considered $\chi^{2}(248$ g.1.) $=285.7339$.

58 Internet World Stats (2005) 'Internet users by languages', www.internetworldstats.com/stats7.htm.

\section{APPENDIX 1: DEFINITIVE REASON SCALES FOR ONLINE NEWSPAPER READERSHIP}

The individual is asked to grade from 1-7 their level of agreement or disagreement with the following statements:

Reason scale: search for specific information

SSI1 When I read the newspaper, my objective is to find information on a specific subject.

SSI3 When I read the newspaper, my main motivation is to obtain specific information on a subject.

Reason scale: search for updated news

SUN1 When I read the newspaper, my objective is find out breaking news.

SUN2 When I read the newspaper, my main motivation is to find constantly updated news items.

SUN3 When I read the newspaper, I am interested in the immediacy with which information can be obtained.

SUN4 When I read the newspaper, I am interested in highly current news items.

Reason scale: leisure

LEIS1 When I read the newspaper, one of my objectives is entertainment.

LEIS2 When I read the newspaper, my main motivation is to spend some leisure or free time.

LEIS3 I believe reading the newspaper is a pleasant pastime.

Reason scale: habit

HAB1 I routinely like to read the newspaper each day or most days.

HAB2 I like to spend the same time every day reading the newspaper.

HAB3 I like to read the newspaper every day at approximately the same time. 